\title{
Distribution and Characteristics of Human Plague Cases and Yersinia pestis Isolates from 4 Marmota Plague Foci, China, 1950-2019
}

\author{
Zhaokai He, ${ }^{1}$ Baiqing Wei, ${ }^{1}$ Yujiang Zhang, ${ }^{1}$ Jun Liu, ${ }^{1}$ Jinxiao Xi, ${ }^{1}$ \\ Dunzhu Ciren, ${ }^{1}$ Teng Qi, ${ }^{1}$ Junrong Liang, Ran Duan, Shuai Qin, Dongyue Lv, \\ Yuhuang Chen, Meng Xiao, Rong Fan, Zhizhong Song, Huaiqi Jing, Xin Wang
}

We analyzed epidemiologic characteristics and distribution of 1,067 human plague cases and 5,958 Yersinia pestis isolates collected from humans, host animals, and insect vectors during 1950-2019 in 4 Marmota plague foci in China. The case-fatality rate for plague in humans was $68.88 \%$; the overall trend slowly decreased over time but fluctuated greatly. Most human cases (98.31\%) and isolates (82.06\%) identified from any source were from the Marmota himalayana plague focus. The tendency among human cases could be divided into 3 stages: 1950-1969, 1970-2003, and 2004-2019. The Marmota sibirica plague focus has not had identified human cases nor isolates since 1926. However, in the other 3 foci, Y. pestis continues to circulate among animal hosts; ecologic factors might affect local $Y$. pestis activity. Marmota plague foci are active in China, and the epidemic boundary is constantly expanding, posing a potential threat to domestic and global public health.

Author affiliations: National Institute for Communicable Disease Control and Prevention, Beijing, China (Z. He, J. Liang, R. Duan,

S. Qin, D. Lv, M. Xiao, R. Fan, H. Jing, X. Wang); Qinghai Institute for Endemic Disease Control and Prevention, Xining, China (B. Wei); Center for Disease Control and Prevention of Xinjiang Uygur Autonomous Region, Urumqi, China (Y. Zhang); Inner Mongolia Autonomous Region Comprehensive Center for Disease Control and Prevention, Hohhot, China (J. Liu); Gansu Provincial Centre for Disease Control and Prevention, Lanzhou, China (J. Xi); Center for Disease Control and Prevention of Tibet Autonomous Region, Lhasa, China (D. Ciren); Sichuan Center for Disease Control and Prevention, Chengdu, China (T. Qi);

Shenzhen Nanshan Maternity and Child Healthcare Hospital, Shenzhen, China (Y. Chen); Yunnan Center for Disease Control and Prevention, Kunming, China (Z. Song)

DOI: https://doi.org/10.3201/eid2710.202239
Dlague is a highly virulent fleaborne zoonotic dis1 ease caused by the bacterium Yersinia pestis $(1,2)$. Humans can acquire plague through contact with infectious animal tissues or through inhalation. $\mathrm{Hu}-$ man contact with infectious animal tissues usually occurs when hunting, trapping, skinning, or handling meat of infected animals. Humans infected through animal contact can develop pneumonic plague and, if not treated, spread their infections to other persons by coughing infectious respiratory droplets. Over the course of human history, plague pandemics have caused hundreds of millions of deaths around the world (3-5). Currently, the Democratic Republic of the Congo and Madagascar in Africa are the most severe plague epidemic areas; human cases are reported in Madagascar almost every year (6-10). Plague outbreaks also have caused major public health crises in China. In the first half of the 20th Century, Y. pestis caused several large epidemics and nearly 1 million deaths (11-17).

Plague foci in China are divided into 12 types on the basis of geographic landscape, host, vector, and $Y$. pestis ecotype characteristics (18). Among these, 4 are Marmota (marmot) foci: the Marmota himalayana (Himalayan marmot) plague focus, located in the QinghaiTibet Plateau; the Marmota baibacina-Spermophilus undulatus (gray marmot-long-tailed ground squirrel) plague focus, in the Tianshan Mountains; the Marmota caudata (red marmot) plague focus, in the Pamir Plateau; and the Marmota sibirica (Tarbagan marmot) plague focus, in the Hulun Buir Plateau of Inner Mongolia. 
The Marmota himalayana plague focus is the largest and the most active foci in China. This focus covers $>443,290 \mathrm{~km}^{2}$ and, before the 1990s, most human cases occurred here. Since the 1990s, rat-associated plague epidemics have erupted in southern China, but beginning in 2004, the Marmota himalayana plague focus re-emerged as the main source of human cases. Outbreaks have occurred every few years in this focus.

Ecologic factors, including relevant environmental variables, have strong impacts on the shift between periods of inactivity, when plague is maintained at low levels of transmission among its animal reservoirs, and periods of activity, when rates of transmission greatly increase and cause widespread die-offs among susceptible rodents and increased numbers of human cases (19-22). Because of limitations of experimental technology and economic conditions, plague cases before 1958 were confirmed only by clinical symptoms, such as sudden high fever and lymphadenopathy; human cases usually were accompanied by increased rates of rodent deaths in the area before or at the early stage of human illnesses. Since the 1950s, China has strengthened plague surveillance and control and the number of human cases has decreased rapidly. Cases in the Marmota plague foci have continued to slowly decline; nevertheless, the combined numbers of cases from these foci during 1950-2019 exceeded the total number of plague cases in the United States during 1900-2012 (23).

Currently, most human cases in China occur in the Marmota plague foci. We investigated the distribution and characteristics of human plague cases and $Y$. pestis isolates recovered from animal hosts (mainly marmots) and insect vectors (mainly fleas) during 1950-2019. We describe the prevalence of $Y$. pestis in humans, animal hosts, and insect vectors of China.

\section{Methods}

\section{Data Sources and Analyses}

We included human cases and Y. pestis isolates from Marmota plague foci in China collected during 19502019. We applied descriptive statistics to analyze the distribution of isolates and human cases for each year (Figure 1-4) and for 5-year intervals (Figure 5). The main sources of data were 2 texts on the history of plague in China $(24,25)$ and surveillance data of plague obtained from the regions comprising the Marmota plague foci, namely Qinghai Province (Qinghai), Gansu Province (Gansu), Tibet Autonomous Region (Tibet), Sichuan Province (Sichuan), Xinjiang Uygur Autonomous Region (Xinjiang), and Inner Mongolia Autonomous Region (Inner Mongolia) (26). These foci contain vast lands away from human habitation and surveillance efforts over time have gradually focused more intensely on the spots within these foci where plague is prevalent in marmots and found near human habitations.

The sources of Y. pestis isolates in Marmota plague foci were animals found dead in the environment, plague patients, insect vectors, and a few live animals. Samples collected from animals found dead in the environment showed most animals died of plague.

\section{Diagnosis of Human Plague Cases}

Human cases before 1958 included in the study mainly were confirmed by clinical and epidemiologic investigation based on symptoms, as stated. Human cases after 1958 included in the study had been confirmed by microbiological or serologic diagnosis.

\section{Results}

Landscape, Host, Vector, and Other Ecologic Features The Marmota himalayana plague focus, identified in 1954, covers Qinghai, Gansu, Tibet, Sichuan, and Xinjiang
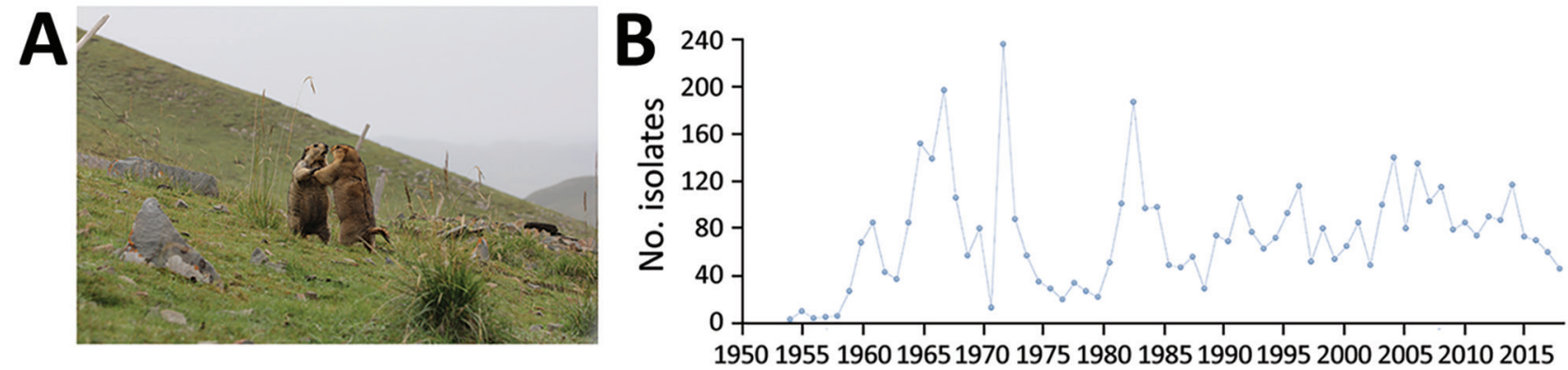

Figure 1. Plague ecology and surveillance of Yersinia pestis in the Marmota himalayana plague focus, Qinghai-Tibet Plateau, China, 1950-2019. This focus area encompasses Qinghai Province, Gansu Province, Tibet Autonomous Region, Sichuan Province, and Xinjiang Uygur Autonomous Region. A) The Himalayan marmot (M. himalayana), the predominant marmot species in this focus. Photograph by Xin Wang. B) Number of Y. pestis isolates collected from humans, animal hosts, and insect vectors (mostly Callopsylla dolabris and Oropsylla silantiewi fleas) in the focus. 

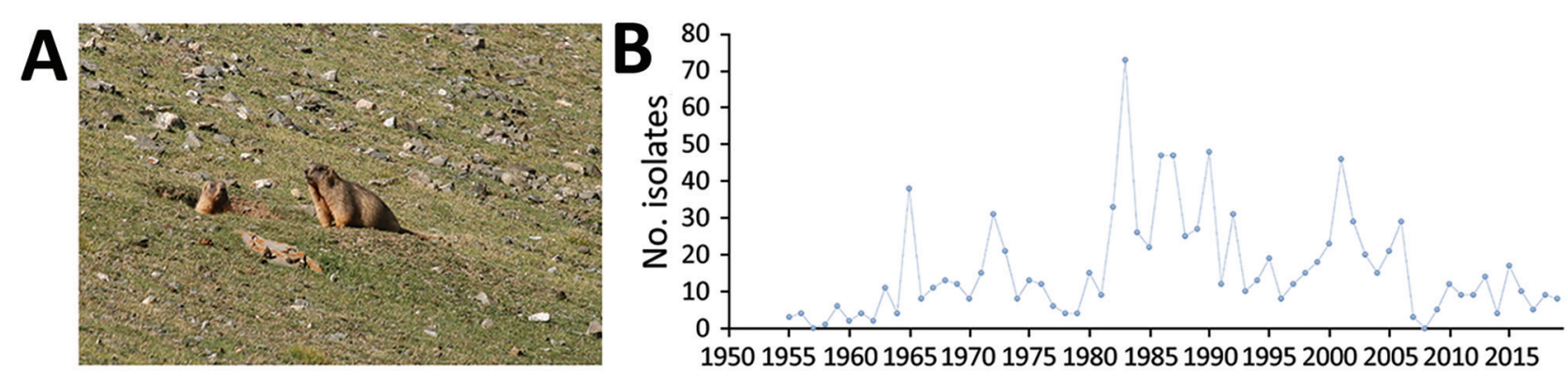

Figure 2. Plague ecology and surveillance of Yersinia pestis in the Marmota baibacina-Spermophilus undulatus plague focus of the Tianshan Mountains, Xinjiang Uygur Autonomous Region, China, 1950-2019. A) The gray marmot (M. baibacina), the predominant marmot species in this focus. Photograph by Yujiang Zhang. The long-tailed ground squirrel (S. undulatus) also is an Y. pestis host in the focus. B) Number of Y. pestis isolates collected from humans, animal hosts, and insect vectors (mostly Oropsylla silantiewi and Citellophilus tesquorum fleas) in the focus.

(Figure 6). The main host is the Himalayan marmot (Figure 1, panel A), which inhabits high-frigid shrub habitats and meadow-steppe zone at altitudes of 2,700-5,450 m. Callopsylla dolabris and Oropsylla silantiewi fleas are the main insect vectors (Table 1).

The Marmota baibacina-Spermophilus undulatus plague focus was identified in 1955 and is in Xinjiang (Figure 6). The main animal hosts are the gray marmot (Figure 2, panel A) and long-tailed ground squirrel, both of which inhabit forest meadow-steppe and alpine meadow-steppe zones at altitudes of 1,6004,000 m. O. silantiewi fleas and Citellophilus tesquorum fleas are the main vectors.

The Marmota caudata plague focus was identified in 1956 and is located in Xinjiang (Figure 6). The main host is the red marmot, also known as the golden or long-tailed marmot (Figure 3, panel A), which inhabits the alpine steppe zone at altitudes of 2,800-5,000 m, but most live in the higher end of the range at 3,800-5,000 m. O. silantiewi fleas are the main insect vector.

The Marmota sibirica plague focus is located at the border of China, Mongolia, and Russia. The focus, located in Inner Mongolia (Figure 6), was identified in 1923. The main animal host is the Tarbagan marmot (Figure 7, panel A), which inhabits low mountains and hills and the meadow-steppe zone at altitudes of $600-800 \mathrm{~m}$. O. silantiewi fleas are the main insect vector in this focus. No Y. pestis strains have been isolated from the Marmota sibirica plague focus since 1926; we only measured host surveillance in this focus. Surveillance of the Tarbagan marmot population density was started in 1978 (Figure 7, panel B). Professionals from the local Chinese Center for Disease Control and Prevention office conduct surveillance by counting the number of marmots observed along survey routes, then calculate density by dividing the number of marmots observed by the size of area. During 1978-2019, the density of M. sibirica in the focus area was highest in 2004, 1.274 marmots/ hectare $\left(10,000 \mathrm{~m}^{2}\right)$ and lowest in 1989 (0 per hectare) (Figure 7, panel B).

\section{Distribution Characteristics of $Y$. pestis Isolates}

During 1950-2019, a total of 5,958 Y. pestis isolates were recovered from Marmota plague foci in China. On average, $85.11 Y$. pestis isolates were recovered each year. The years with the most isolates were 1967
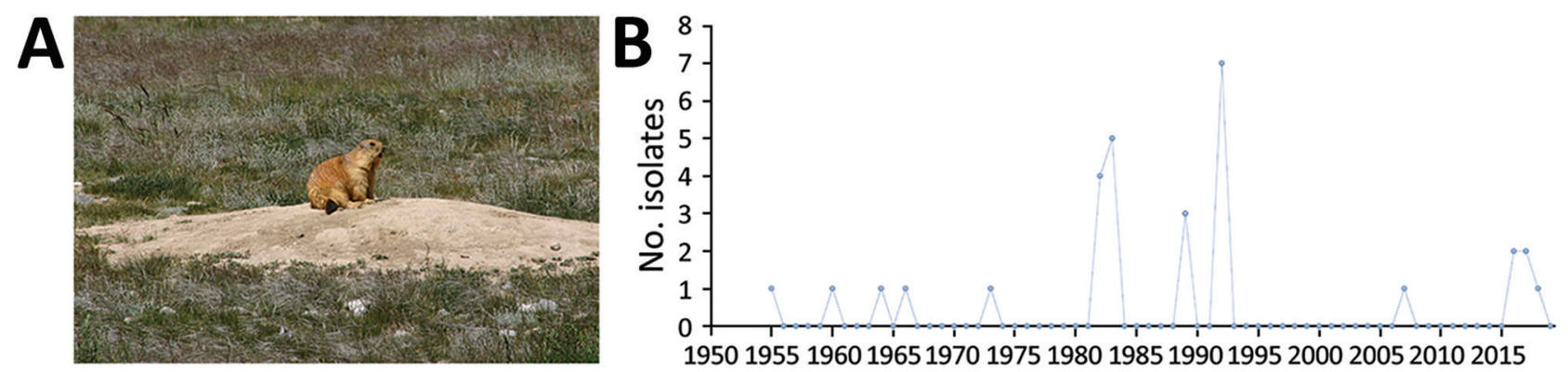

Figure 3. Plague ecology and surveillance of Yersinia pestis in the Marmota caudata plague focus of the Pamir Plateau, Xinjiang Uygur Autonomous Region, China, 1950-2019. A) The red marmot (M. caudata), the predominant marmot species in this focus. Photograph by Yujiang Zhang. B) Number of $Y$. pestis isolates collected from humans, animal hosts, and insect vectors (mostly Oropsylla silantiewi fleas) in the focus. 


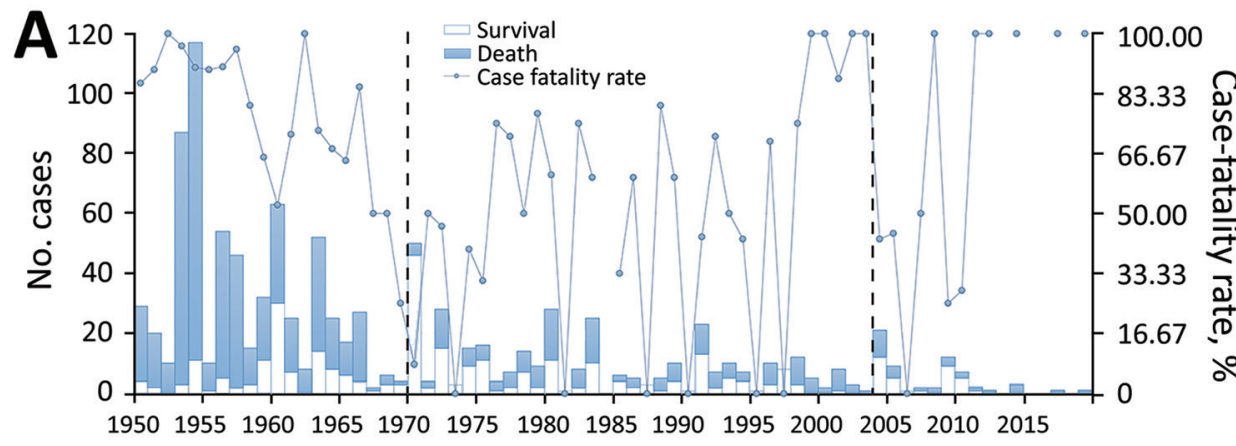

B

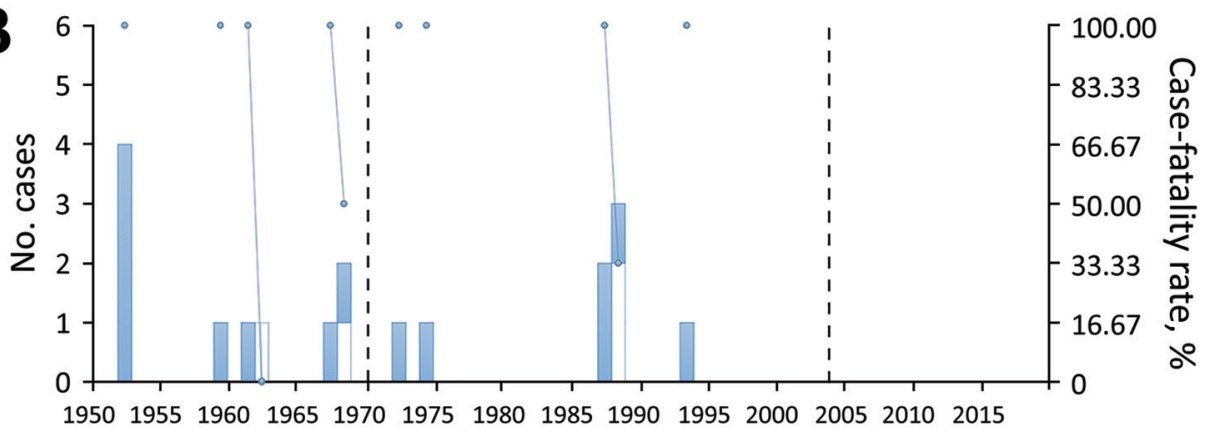

Figure 4. Frequency of human plague cases and case-fatality rates in 2 Marmota plague foci, China, 1950-2019. A) Marmota himalayana plague focus of the Qinghai-Tibet Plateau, which includes Qinghai Province, Gansu Province, Tibet Autonomous Region, Sichuan Province, and Xinjiang Uygur Autonomous Region. B) Marmota baibacinaSpermophilus undulatus plague focus includes Xinjiang Uygur Autonomous Region.
(208 isolates), 1983 (265 isolates), and 1972 (267 isolates). No $Y$. pestis isolates were recovered from the Marmota sibirica plague focus during this period.

$Y$. pestis has been isolated in the Marmota himalayana plague focus every year since the first isolate was recovered in 1954. During 1954-2019, 4,889 isolates were collected from the focus. In the Marmota baibacina-Spermophilus undulatus plague focus, Y. pestis isolates were first recovered in 1955 and a total of
1,039 isolates were collected by 2019. In the Marmota caudata plague focus, $Y$. pestis was first isolated in 1956 and 30 isolates were collected by 2019.

\section{Epidemiologic Characteristics of Human Plague Cases} During 1950-2019, total of 1,067 human plague cases have occurred in the 4 Marmota plague foci in China, including 735 deaths. The average case-fatality rate was $68.88 \%, 15.24$ cases annually. Among all plague
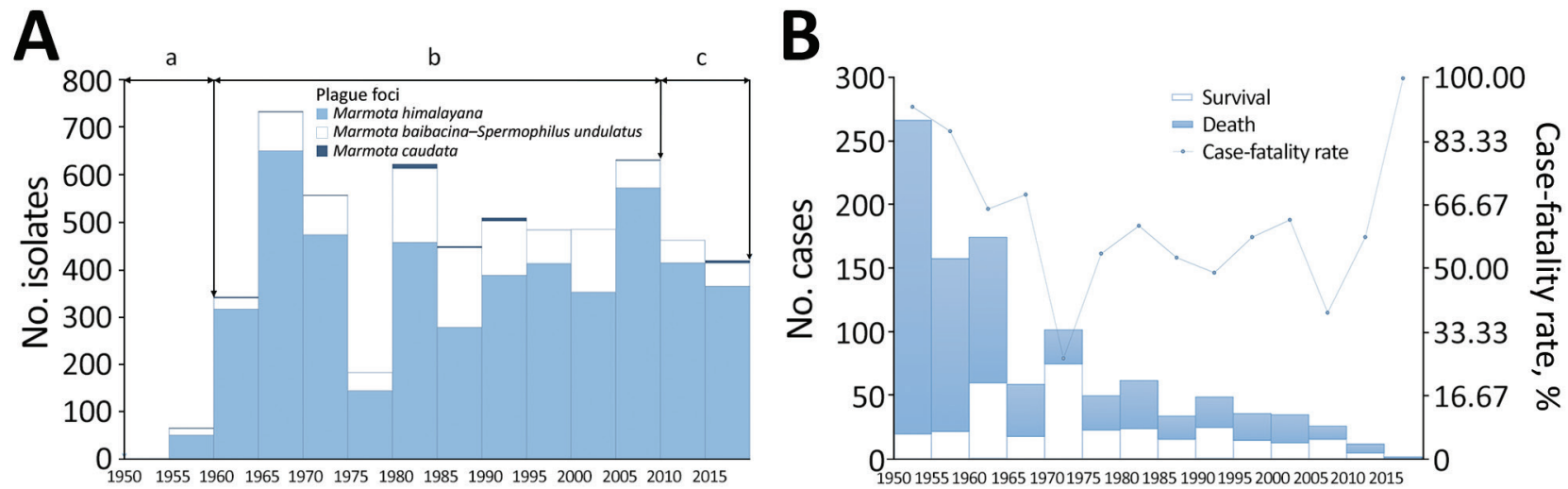

Figure 5. Number of Yersinia pestis isolates and human plague cases in Marmota plague foci, China, 1950-2019. Columns represent 5-year intervals. The 3 plague foci from which Y. pestis isolates have been collected are the Marmota himalayana plague focus of the Qinghai-Tibet Plateau, which includes Qinghai Province, Gansu Province, Tibet Autonomous Region, Sichuan Province, and Xinjiang Uygur Autonomous Region; the Marmota baibacina-Spermophilus undulatus plague focus of the Tianshan Mountains, Xinjiang Uygur Autonomous Region; and the Marmota caudata plague focus of the Pamir Plateau, Xinjiang Uygur Autonomous Region. A) Number of Y. pestis isolates collected from humans, animal hosts, and insect vectors. Lowercase letters at top indicate periods of isolate collection: a) early attempts during 1950-1959; b) increased diagnosis and animal plague surveillance increased number isolates collected during 1960-2009; and c) decrease in isolates likely due to decreasing numbers of dead marmot species found around active Y. pestis areas during 2010-2019. B) Number of human plague cases and case-fatality rates. 

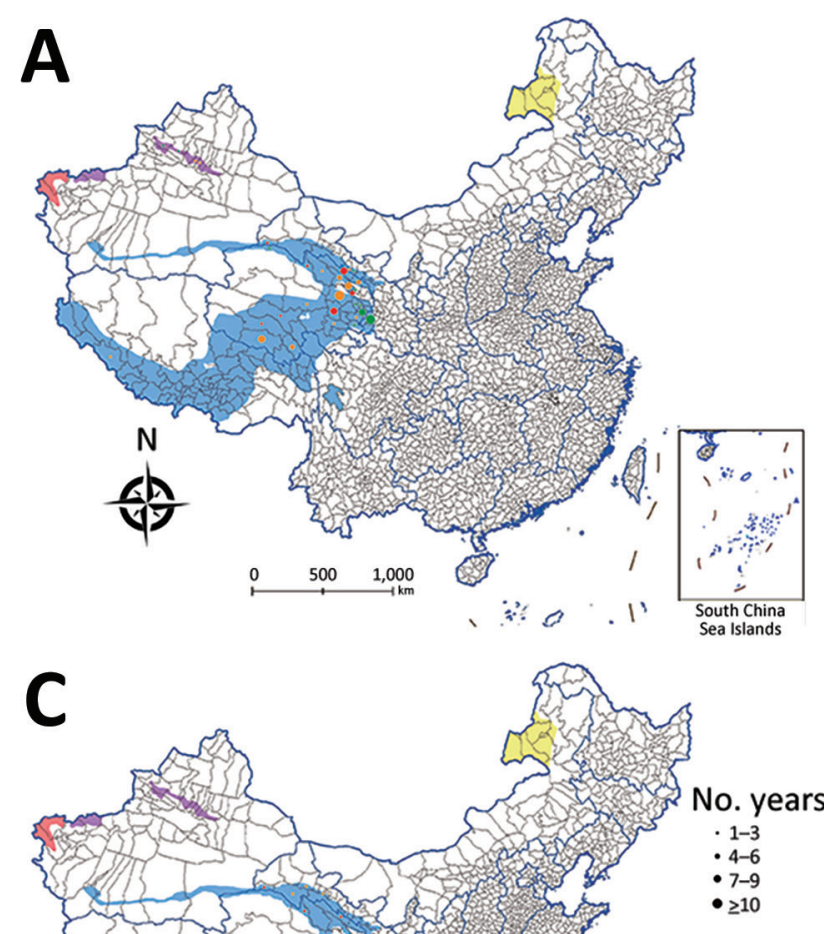

No. periods

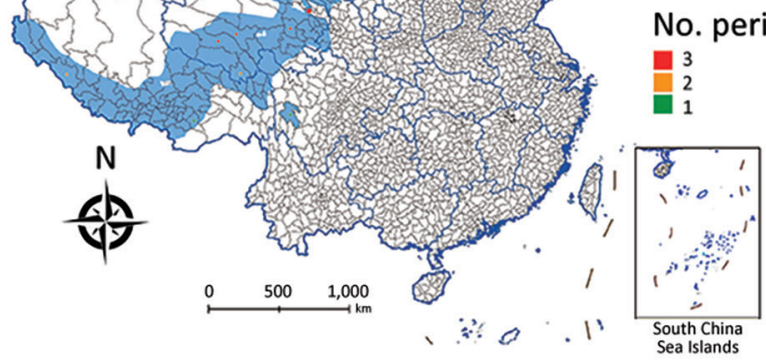

cases, 690 were confirmed by laboratory or serologic diagnosis; 377 were diagnosed by clinical and epidemiologic investigations. Most cases occurred in 1953 (87 cases), 1954 (117 cases), and 1960 (63 cases).

During 1950-2019, the Marmota himalayana plague focus had the most $(1,049)$ human cases (Figure 4, panel A); only 18 cases have occurred in the Marmota baibacina-Spermophilus undulatus plague focus (Figure 4, panel

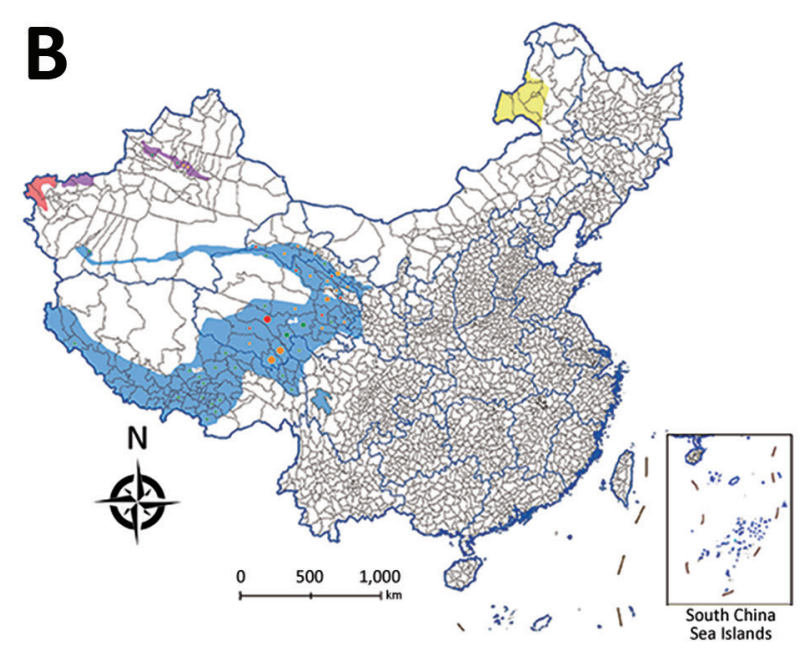

Figure 6. Human plague cases detected in 4 Marmota plague foci, China. A) 1950-1969; B) 1970-2003; C) 2004-2019. Dot size indicates the number of years during which plague occurred in each timeframe; dot colors indicates number of periods $(A, B, C)$ during which plague occurred for each location. Blue shading indicates the Marmota himalayana plague focus; purple shading indicates the Marmota baibacinaSpermophilus undulatus plague focus; red shading indicates the Marmota caudata plague focus; and yellow shading indicates the Marmota sibirica plague focus.
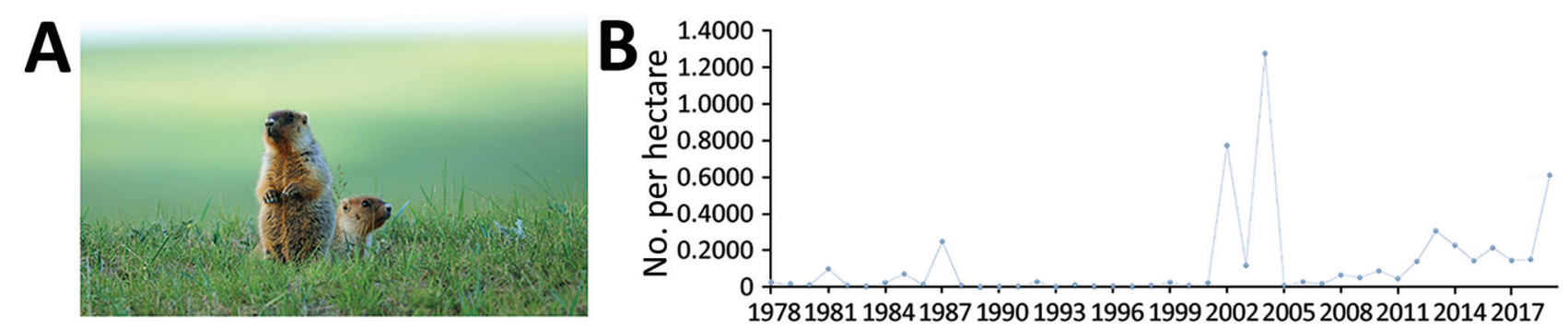

Figure 7. Ecology and surveillance of marmots in the Marmota sibirica plague focus of the Hulun Buir Plateau, Inner Mongolia, 19502019. A) Tarbagan marmot (M. sibirica), the predominant marmot species in this focus. Photograph by Jun Liu. B) Average density of this species in the focus area. Tarbagan marmots host Oropsylla silantiewi fleas, a known vector of Yersinia pestis, but no Y. pestis isolate has been collected from humans, animal hosts, or insect vectors in this focus since 1926. 
Table 1. Ecologic characteristics of Marmota plague foci, China, 1950-2019

\begin{tabular}{|c|c|c|c|c|}
\hline Characteristics & Marmota himalayana* & $\begin{array}{c}\text { Marmota baibacina- } \\
\text { Spermophilus undulatus } \dagger\end{array}$ & Marmota caudatał & Marmota sibirica§ \\
\hline Year Yersinia pestis first isolated & 1954 & 1955 & 1956 & 1923 \\
\hline Regions & $\begin{array}{c}\text { Qinghai Province, } \\
\text { Gansu Province, Tibet } \\
\text { Autonomous Region, } \\
\text { Sichuan Province, } \\
\text { Xinjiang Uygur } \\
\text { Autonomous Region }\end{array}$ & $\begin{array}{c}\text { Xinjiang Uygur } \\
\text { Autonomous Region }\end{array}$ & $\begin{array}{c}\text { Xinjiang Uygur } \\
\text { Autonomous Region }\end{array}$ & $\begin{array}{c}\text { Inner Mongolia } \\
\text { Autonomous Region }\end{array}$ \\
\hline Hosts & Himalayan marmot & $\begin{array}{l}\text { Gray marmot, long-tailed } \\
\text { ground squirrel }\end{array}$ & Red marmot & Tarbagan marmot \\
\hline Vectors & $\begin{array}{c}\text { Callopsylla dolabris, } \\
\text { Oropsylla silantiewi } \\
\text { fleas }\end{array}$ & $\begin{array}{l}\text { O. silantiewi, Citellophilus } \\
\text { tesquorum fleas }\end{array}$ & O. silantiewi fleas & O. silantiewi fleas \\
\hline Altitude & $2,700-5,450 \mathrm{~m}$ & $1,600-4,000 \mathrm{~m}$ & $2,800-5,000 \mathrm{~m}$ & $600-800 \mathrm{~m}$ \\
\hline \multicolumn{5}{|l|}{ Hibernation } \\
\hline Start & September-October & September & Mid-September & $\begin{array}{l}\text { Late September-early } \\
\text { October }\end{array}$ \\
\hline End & Late March-mid-April & Early- to mid-April & Early April & Late March-early April \\
\hline $\begin{array}{l}\text { Animal plague season } \\
\text { Peak }\end{array}$ & $\begin{array}{l}\text { April-October } \\
\text { June-July }\end{array}$ & $\begin{array}{l}\text { May-September } \\
\text { July }\end{array}$ & $\begin{array}{l}\text { May-August } \\
\text { July }\end{array}$ & $\begin{array}{l}\text { NAT } \\
\text { NAI } \\
\end{array}$ \\
\hline Habitat & $\begin{array}{l}\text { High-frigid shrubs, } \\
\text { meadow-steppe }\end{array}$ & $\begin{array}{l}\text { Forest-meadow-steppe, } \\
\text { alpine meadow-steppe }\end{array}$ & Alpine steppe & $\begin{array}{l}\text { Low mountains and } \\
\text { hills, meadow-steppe }\end{array}$ \\
\hline $\begin{array}{l}\text { *Qinghai-Tibet Plateau. } \\
\text { †Tianshan Mountains. } \\
\text { tPamirs Plateau. } \\
\text { §Hulun Buir Plateau of Inner Mongolia. } \\
\text { INo Y. pestis isolated since 1926. }\end{array}$ & & & & \\
\hline
\end{tabular}

The patterns of decline for human cases are different in the 2 most active foci (Figure 4). In the Marmota himalayana plague focus, the number of cases was relatively high and periodically fluctuated, but both the number and frequency of peaks declined over time (Figure 4, panel A). During 1950-1969, the number of cases was high and the peak interval was short; during 1970-2003, the number of cases decreased sharply and the interval was longer; after 2004, the number of cases declined further and in some years no cases were reported. In contrast, the pattern of decline in human cases in the Marmota baibacina-Spermophilus undulatus plague focus has had longer intervals. In several years $\leq 4$ human cases occurred and no case has been reported since 1994 (Figure 4, panel B). During 1950-2019, primary and secondary pneumonic plague accounted for $69.26 \%$ $(739 / 1,067)$ of cases, among which the case-fatality rate was $75.10 \%$ (555/739) (Table 2). The rate of other plague types, such as bubonic and septicemic, was $54.88 \%(180 / 328)$ (Table 2).

\section{Discussion}

Four Marmota plague foci have been identified and classified in China. Each focus is characterized by the marmot species that serves as the primary $Y$. pestis host in the region, but other animals in these areas also can be infected, usually with highly virulent $Y$. pestis strains (27). The 4 foci are active areas where animal and human plague epidemics continue in China. Except for the Marmota sibirica plague focus, most foci are in western China (Figure 6). Climatic conditions, such as long winters with heavy snow, are characteristic of these foci, as are unique geographic features, such as frozen glacial soils, cold desert plateaus, alpine grasslands, and river wetlands. Many rare wild animals inhabit these plateaus, and the human population is sparse. Little human disturbance and rela-

\begin{tabular}{|c|c|c|c|}
\hline Focus & Pneumonic plague & Other plague types $\dagger$ & Total \\
\hline Marmota himalayanał & $75.03(544 / 725)$ & $54.63(177 / 324)$ & $68.73(721 / 1,049)$ \\
\hline Marmota baibacina-Spermophilus undulatus§ & $78.57(11 / 14)$ & $75.00(3 / 4)$ & $77.78(14 / 18)$ \\
\hline Marmota caudatađ & 0 & 0 & 0 \\
\hline Marmota sibirica\# & 0 & 0 & 0 \\
\hline Total case-fatality rate & $75.10(555 / 739)$ & $54.88(180 / 328)$ & $68.88(735 / 1,067)$ \\
\hline $\begin{array}{l}\text { *Data are reported as case-fatality rate, \% (no. deaths } \\
\text { †Including bubonic, septicemic, and other types. } \\
\text { †Qinghai-Tibet Plateau. } \\
\text { §Tianshan Mountains. } \\
\text { đPamirs Plateau. }\end{array}$ & & & \\
\hline
\end{tabular}


tively stable plague ecology could be conducive to maintaining the ecologic balance and active plague status of these foci (21).

The Marmota sibirica plague focus is located at the junction of China, Mongolia, and Russia, and 2 plague epidemics occurred in this focus in the early 20th Century. Of note, no human case has been reported in this part of China since 1923, and Y. pestis has not been isolated from there since 1926. However, cases of animal and human plague from this focus are reported in Mongolia and Russia (11-17,28-35). The main reason for the lack of human cases in this focus in China is the considerable decrease in Tarbagan marmot populations, which are believed to be due to ecologic changes and increased human activity. The development of animal husbandry, such as raising sheep that graze in marmot habitats in the region, and environmental disruption due to transportation and farming activities, have caused irreversible damage to the Tarbagan marmot habitat. In addition, sale of marmot skins and meat have depleted the population; $\approx 2,500,000$ marmot skins were purchased in 1910, the peak year. In addition, a large fire in 1987 caused devastating damage to the Tarbagan marmot habitat and killed $\approx 200,000$ marmots (36).

When the existing ecologic balance is disrupted, for instance due to habitat damage, the number of $Y$. pestis hosts and the host density changes, thus affecting the survival of the bacterium. Y. pestis circulates among animal and vector hosts within a limited range and with discrete distribution where it seldom causes human plague and is rarely detected by regular surveillance. The interactions between host, pathogen, and environment seem to be gradually settling into a period of relative inactivity in all Marmota plague foci $(19,21)$.

China began attempts to isolate Y. pestis during 1950-1959 and the number of isolates recovered was relatively low (Figure 5). During 1960-2009, the number of collected isolates greatly increased, mainly due to improved case diagnosis and animal plague surveillance and plague diagnosis is confirmed through pathogen isolation or other laboratory evidence. During 2010-2019, the number of $Y$. pestis isolates decreased in China, which seems to be related to the decrease of marmots found dead around active plague locations and human cases. In 1953, China established specialized plague investigation agencies for the Marmota plague foci. Many unsuccessful attempts at eradicating $Y$. pestis in these foci have demonstrated that plague is inherent in these areas and cannot be eliminated by large scale attempts to kill rodent hosts $(21,27,37)$.
After these unsuccessful attempts to reduce the possibility of human exposure to plague, Y. pestis elimination efforts have focused more on key locations and key seasons, particularly in locations with epidemic activity and during the peak marmot and flea breeding seasons (38). Long-term training and education among clinicians has resulted in more timely diagnosis, treatment, and reporting of human plague cases (39). Improving humans' awareness about plague and their ability to protect themselves seems to have reduced their exposure to marmots and infected fleas. For future surveillance, appropriate typing methods for tracking the spread of certain $Y$. pestis strains are needed. The Y. pestis genome remains stable in Marmota plague foci, enabling Y. pestis to maintain its high pathogenicity and virulence, and most $Y$. pestis strains in the Marmota plague foci are highly virulent (27). Single-nucleotide polymorphism typing and other phylogenic studies have shown that $Y$. pestis clusters geographically in China; it could take years to accumulate several mutations within the same focus or region (40).

During 1950-2019, human cases in the Marmota plague foci of China were mainly concentrated in the Marmota himalayana focus, which has remained active since it was identified in $1954(41,42)$. Only 18 human cases have been reported in the Marmota baibacinaSpermophilus undulatus plague focus. No human case has ever been reported in the Marmota caudata plague focus since it was identified in 1956, which can be attributed to limited human habitation and limited exposure to infected animals. No human cases have been reported in the Marmota sibirica plague focus since 1923; marmot density in this region generally is low but has been reported as being abnormally high for several years (Figure 7, panel B), perhaps because earlier sampling was not representative of the whole because survey areas were limited. Recent ecologic protection measures in this region might raise the Tarbagan marmot density, which could increase the numbers of $Y$. pestis-infected marmots. Previously scattered pockets of $Y$. pestis infection might enlarge and eventually merge with other pockets, leading to a threat of increased spread among marmots and heightened human plague risk $(19,21)$.

Human cases in the Marmota plague foci have shown a decreasing trend, but a slower decrease than in other plague foci of China. Marmota plague foci had a relatively high average case-fatality rate of $68.88 \%$ during 1950-2019 because of a higher proportion of pneumonic cases, which had a much higher average case-fatality rate $(75.10 \%)$ than other plague types. In contrast, bubonic and septicemic plague had a com- 
bined case-fatality rate of $54.88 \%$. Because pneumonic plague can be transmitted directly between humans without vector involvement $(37,43)$, it can spread rapidly in densely populated areas, as has occurred in several pandemics $(3-5,44)$. In China, human cases before 1958 were pneumonic plague and had an extremely high fatality rate of $92.57 \%$ (Figure 5, panel B). Delayed medical treatment and misdiagnosis might contribute to high fatality rates. For instance, when horses were the main form of transportation, most human cases progressed to pneumonic plague because timely access to treatment was not possible; large-scale outbreaks with human-to-human transmission and high case-fatality rates were reported. At the same time, some sporadic or bubonic cases might have been missed. Nevertheless, the possibility of misdiagnosis in the past is estimated to be low because of high case-fatality rates, obvious clinical features, and epidemiologic evidence of rodent deaths before or at the early stage of illness and, in some cases, human-to-human transmission.

In recent years, the most active region of the Marmota himalayana plague focus has been Subei County in Gansu, where animal plague is extremely epizootic and the case-fatality rate is high. However, the area is sparsely populated, only $\approx 15,100$ residents in $66,700 \mathrm{~km}^{2}$, and improvements in early detection, diagnosis, and treatment have been achieved. Although the case-fatality rate is high, the disease is unlikely to spread to other areas because few persons travel outside Subei and because timely diagnosis and control help prevent further spread. Plague in the area mainly is limited to family groups, occasionally affecting neighbors or medical staff. In some years, the area had a high number of cases, but the case-fatality rate was low compared with the extremely high casefatality rate of most years (Figure 5). Despite multiple pneumonic plague outbreaks in these epidemic spots, doctors and the public are highly vigilant and timely and effective antimicrobial drug treatment has improved patient prognoses. In 2009, for example, when an index case was identified in the county, a national medical team of experts from Beijing and Qinghai arrived at the scene to treat human plague cases and mitigate further spread (41).

The main transmission route of plague in the Marmota plague foci in China is through wounds incurred during marmot skinning, bites from infected fleas, or human-to-human transmission by pneumonic patients. In rare cases, shepherd dogs with pneumonic plague have transmitted plague to herders $(41,42)$. In addition, Tibetan sheep (Ovis aries) are a host species unique to the Marmota himalayana plague focus and the number of human cases caused by sheep infections in this foci is second only to those caused by marmots. During 1950-2019, a total of 80 related human plague cases were reported, most caused by skinning and eating infected sheep. Tibetan sheep become infected through consuming animals that have died of plague or via bites from infected fleas. The sheep especially like chewing bone remains, which leads to oral mucosa damage and $Y$. pestis infection $(45,46)$. Human cases have major occupational characteristics; most victims are marmot poachers, local herdsmen, and hired herders (42). Because of prohibitions on hunting, trafficking, and sales of marmots and related laws and education on self-protection, the number of poachers and herdsmen infection has decreased sharply. Recently, hired herders have become the most likely to be infected because they received less education on avoiding plague and engaged in skinning and eating marmots. In addition, transportation to Marmota plague foci has become convenient, greatly increasing the risk for long-distance transmission when persons leave foci plague infected with $Y$. pestis or carrying $Y$. pestis infected flea vectors. Illegal hunting and trading of marmots for their meat and skins also occasionally has occurred and live marmots are being shipped to densely populated cities, especially to some southern cities, where eating game animals is popular. Because of their unique geographic location and environment, Marmota plague foci have become excellent areas for scientific research, exploration, and tourism. Global tourists can easily reach these foci, which increases the risk for $Y$. pestis infection. Moreover, herdsmen from plague foci also can reach domestic and foreign cities within a day; thus, the increasing trend of plague transmission in densely populated areas (47). For example, in 2019, two patients with respiratory symptoms in the Meriones unguiculatus plague focus of Inner Mongolia were transferred to Chaoyang Hospital in Beijing where pneumonic plague later was diagnosed (48). This example demonstrates that human plague is a rare but serious infectious disease that still poses a public health risk in China and worldwide.

In summary, most human plague cases and $Y$. pestis isolates originating in the Marmota plague foci of China since 1950 have been concentrated in the Marmota himalayana plague focus. Cases from this region exhibit 3 major characteristics: the frequency of human cases during 1950-2019 slowly declined but fluctuated greatly, in sharp contrast to the rapid declines in other plague foci in China; human cases are primarily distributed in the Qinghai-Tibet Plateau and Tianshan Mountains of China; and index case-patients were mainly infected through wounds 
incurred while skinning infected marmots. The Qinghai-Tibet Plateau and Tianshan Mountain regions have large land areas but sparse human populations and poor or no medical facilities. Most Y. pestis strains derived from marmots are highly virulent (27), which results in outbreaks of pneumonic plague, often with higher case-fatality rates. The number of dormant foci have increased and active foci are greatly reduced in China, especially in some southern regions where one of the largest plague outbreaks occurred and primarily associated with exposure of humans to rat flea bites (21). In sharp contrast, the Marmota himalayana plague focus is sparsely populated, and the interaction between the environment, host, and Y. pestis is relatively balanced, which is conductive to the sustained prevalence of plague. As was the case for the 2017 outbreak in Madagascar (8), the outcome of human plague in the Marmota plague foci of China is uncertain, and risk for long-distance transmission continues, which could have worldwide public health effects. Therefore, plague prevention and control remain a strong priority in China.

\section{Acknowledgments}

We thank American Journal Experts (submission no. 47MMS9GB) and Charlesworth author services (paper no. 75168 ) for their critical editing and helpful comments regarding our manuscript.

This work was supported by the National Sci-Tech Key Project (grant nos. 2018ZX10713-003-002 and 2018ZX10713-001-002).

\section{About the Author}

Dr. He is an epidemiologist at the Chinese Center for Disease Control and Prevention. Her research interests include pathogenic Yersinia and emerging infectious diseases.

\section{References}

1. Pollitzer R. Plague. World Health Organization monograph series no. 22. Geneva: The Organization;; 1954 [cited 2021 Aug 11]. http://apps.who.int/iris/bitstream/10665/41628/1/WHO_MONO_22.pdf

2. Dennis DT, Mead PS. Yersinia species, including plague. In: Mandell GL, Bennet JE, Dolin R, editors. Principles and practice of infectious diseases, 7th ed. Philadelphia: Elsevier; 2010. p. 2943-53.

3. Perry RD, Fetherston JD. Yersinia pestis - etiologic agent of plague. Clin Microbiol Rev. 1997;10:35-66. https:/ / doi. org/10.1128/CMR.10.1.35

4. Drancourt M, Raoult D. Molecular history of plague. Clin Microbiol Infect. 2016;22:911-5. https:/ / doi.org/10.1016/ j.cmi.2016.08.031

5. Wagner DM, Klunk J, Harbeck M, Devault A, Waglechner N, Sahl JW, et al. Yersinia pestis and the plague of Justinian
541-543 AD: a genomic analysis. Lancet Infect Dis. 2014;14:31926. https:/ / doi.org/10.1016/S1473-3099 (13)70323-2

6. Boisier $\mathrm{P}$, Rahalison $\mathrm{L}$, Rasolomaharo M, Ratsitorahina M, Mahafaly M, Razafimahefa M, et al. Epidemiologic features of four successive annual outbreaks of bubonic plague in Mahajanga, Madagascar. Emerg Infect Dis. 2002;8:311-6. https://doi.org/10.3201/eid0803.010250

7. Abedi AA, Shako JC, Gaudart J, Sudre B, Ilunga BK, Shamamba SKB, et al. Ecologic features of plague outbreak areas, Democratic Republic of the Congo, 2004-2014. Emerg Infect Dis. 2018;24:210-20. https:// doi.org/10.3201/eid2402.160122

8. Randremanana R, Andrianaivoarimanana V, Nikolay B, Ramasindrazana B, Paireau J, Ten Bosch QA, et al. Epidemiological characteristics of an urban plague epidemic in Madagascar, August-November, 2017: an outbreak report. Lancet Infect Dis. 2019;19:537-45. https:/ / doi.org/10.1016/ S1473-3099(18)30730-8

9. Mead PS. Plague in Madagascar - a tragic opportunity for improving public health. N Engl J Med. 2018;378:106-8. https://doi.org/10.1056/NEJMp1713881

10. Andrianaivoarimanana V, Piola P, Wagner DM, Rakotomanana F, Maheriniaina V, Andrianalimanana S, et al. Trends of human plague, Madagascar, 1998-2016. Emerg Infect Dis. 2019;25:220-8. https:/ / doi.org/10.3201/ eid2502.171974

11. Lien Teh W, Han CW, Pollitzer R. Plague in Manchuria: I. Observations made during and after the second Manchurian plague epidemic of 1920-21. II. The role of the Tarabagan in the epidemiology of plague. J Hyg (Lond). 1923;21:307-58. https:/ / doi.org/10.1017/S0022172400031521

12. Lien Teh W, Tuck GL, Han CW, Pollitzer R. The second pneumonic plague epidemic in Manchuria, 1920-21: I. A general survey of the outbreak and its course. J Hyg (Lond). 1923;21:262-88. https:/ / doi.org/10.1017/S0022172400031508

13. Lien Teh W, Tuck GL. Investigations into the relationship of the Tarbagan (Mongolian marmot) to plague. Lancet. 1913; 182:529-35. https://doi.org/10.1016/S0140-6736(01)76466-5

14. Lien Teh W, Tuck GL. First report of the north Manchurian plague prevention service. J Hyg (Lond). 1913;13:237-90.21. PubMed https:/ / doi.org/10.1017/s0022172400005404

15. Teh WL. Plague in the orient with special reference to the Manchurian outbreaks. J Hyg (Lond). 1922;21:62-76. https://doi.org/10.1017/S0022172400031223

16. Lien-Teh W. A further note on natural and experimental plague in Tarbagans. J Hyg (Lond). 1924;22:329-34. https:// doi.org/10.1017/S0022172400008263

17. Teh WL, Chun JWH, Pollitzer R. Clinical observations upon the Manchurian plague epidemic, 1920-21. J Hyg (Lond). 1923;21:289-306. https:// doi.org/10.1017/ S002217240003151X

18. Ben-Ari T, Neerinckx S, Agier L, Cazelles B, Xu L, Zhang Z, et al. Identification of Chinese plague foci from long-term epidemiological data. Proc Natl Acad Sci U S A. 2012; 109:8196-201. https:// doi.org/10.1073/pnas.1110585109

19. Heier L, Storvik GO, Davis SA, Viljugrein H, Ageyev VS, Klassovskaya E, et al. Emergence, spread, persistence and fade-out of sylvatic plague in Kazakhstan. Proc Biol Sci. 2011;278:2915-23. https:/ / doi.org/10.1098/ rspb.2010.2614

20. Davis S, Begon M, De Bruyn L, Ageyev VS, Klassovskiy NL, Pole SB, et al. Predictive thresholds for plague in Kazakhstan. Science. 2004;304:736-8. https:/ / doi.org/10.1126/ science. 1095854

21. Wang X, Wei X, Song Z, Wang M, Xi J, Liang J, et al. Mechanism study on a plague outbreak driven by the 
construction of a large reservoir in southwest china (surveillance from 2000-2015). PLoS Negl Trop Dis. 2017; 11:e0005425. https:// doi.org/10.1371/journal.pntd.0005425

22. Stenseth NC, Samia NI, Viljugrein H, Kausrud KL, Begon M, Davis $\mathrm{S}$, et al. Plague dynamics are driven by climate variation. Proc Natl Acad Sci U S A. 2006;103:13110-5. https:/ / doi.org/10.1073/pnas.0602447103

23. Kugeler KJ, Staples JE, Hinckley AF, Gage KL, Mead PS. Epidemiology of human plague in the United States, 19002012. Emerg Infect Dis. 2015;21:16-22. https://doi.org/ 10.3201/eid2101.140564

24. Institute of Epidemiology and Microbiology, Chinese Academy of Medical Sciences. The history of spread of plague in China [in Chinese]. Beijing: People's Medical Publishing House; 1981. p. 33-1794.

25. Xian W. History of plague epidemics [in Chinese]. Guangzhou (China): Epidemic Prevention Center of Guangdong Province Press; 1988.

26. Liu Y, Tan J, Shen E. The atlas of plague and its environment in People's Republic of China [in Chinese]. Beijing: Science Press; 2000.

27. Wang Z, Li C. Qinghai plague [in Chinese]. Beijing: People's Medical Publishing House Press; 2016.

28. Dubyanskiy VM, Yeszhanov AB. Ecology of Yersinia pestis and the epidemiology of plague. In: Yang R, Anisimov A, editors: Yersinia pestis: retrospective and perspective. Advances in experimental medicine and biology, volume 918. Dordrecht: Springer: 2016. https:/ / doi.org/10.1007/ 978-94-024-0890-4_5

29. Pastukhov BN. The epizootic and epidemic situation in the natural foci of plague in the USSR and the prophylactic measures taken. Bull World Health Organ. 1960;23:401-4.

30. Popov NV, Bezsmertny VE, Toporkov VP, Matrosov AN, Knyazeva TV, Kuznetsov AA, et al. Epizootic activity of natural plague foci in the Russian Federation in 2013 and prognosis for the year of 2014 [in Russian]. Problems of Particularly Dangerous Infections. 2014:2;13-8. https:/ / doi.org/10.21055/0370-1069-2014-2-13-18

31. Galdan B, Baatar U, Molotov B, Dashdavaa O. Plague in Mongolia. Vector Borne Zoonotic Dis. 2010;10:69-75. https://doi.org/10.1089/vbz.2009.0047

32. Riehm JM, Tserennorov D, Kiefer D, Stuermer IW, Tomaso H, Zöller L, et al. Yersinia pestis in small rodents, Mongolia. Emerg Infect Dis. 2011;17:1320-2. https:/ / doi.org/ 10.3201/eid1707.100740

33. Riehm JM, Vergnaud G, Kiefer D, Damdindorj T, Dashdavaa O, Khurelsukh T, et al. Yersinia pestis lineages in Mongolia. PLoS One. 2012;7:e30624. https:/ / doi.org/ 10.1371/journal.pone.0030624

34. Jones SD, Amramina AA. Entangled histories of plague ecology in Russia and the USSR. Hist Philos Life Sci. 2018;40:49. https://doi.org/10.1007/s40656-018-0220-3

35. Popov NV, Kuznetsov AA, Matrosov AN, Korzun VM, Verzhutsky DB, Vershinin SA, et al. Epizootic activity of natural plague foci of the Russian Federation in 2008-2017 and forecast for 2018 [in Russian]. Problems of Particularly Dangerous Infections. 2018;4:50-5. https:/ / doi.org/10.21055/ 0370-1069-2018-1-50-55
36. Liu S, Wang Y, Bao S, Bai Y, De Q. The decrease factors of Marmota sibirica in Hulun Buir League [in Chinese]. Neimenggu Preventive Medicine. 1995;20:59-61. http:/ / qikan.cqvip.com/Qikan/Article/ Detail id $=67877898950246004$

37. Ji S. Plague [in Chinese]. Beijing: People's Medical Publishing House Press; 1988.

38. National Health Commission of the People's Republic of China. National plague monitoring scheme 2005 [in Chinese] [cited 2021 Aug 11]. http://www.nhc.gov.cn/wjw/zcjd/201 304/96300482f5e14a7094d74a9238bf76f2.shtml

39. National Health Commission of the People's Republic of China. Diagnostic criteria for plague 2008 [in Chinese] [cited 2021 Aug 11]. http:/ / www.nhc.gov.cn/wjw / s9491/200802/38803.shtml

40. Cui Y, Yu C, Yan Y, Li D, Li Y, Jombart T, et al. Historical variations in mutation rate in an epidemic pathogen, Yersinia pestis. Proc Natl Acad Sci U S A. 2013;110:577-82. https://doi.org/10.1073/pnas.1205750110

41. Wang H, Cui Y, Wang Z, Wang X, Guo Z, Yan Y, et al. A dog-associated primary pneumonic plague in Qinghai Province, China. Clin Infect Dis. 2011;52:185-90. https:// doi.org/10.1093/cid/ciq107

42. Ge P, Xi J, Ding J, Jin F, Zhang H, Guo L, et al. Primary case of human pneumonic plague occurring in a Himalayan marmot natural focus area Gansu Province, China. Int J Infect Dis. 2015;33:67-70. https:/ / doi.org/10.1016/j.ijid.2014.12.044

43. Pechous RD, Sivaraman V, Stasulli NM, Goldman WE. Pneumonic plague: the darker side of Yersinia pestis. Trends Microbiol. 2016;24:190-7. https:/ / doi.org/10.1016/ j.tim.2015.11.008

44. Walløe L. Medieval and modern bubonic plague: some clinical continuities. Med Hist Suppl. 2008;52(S27):59-73. https://doi.org/10.1017/S0025727300072094

45. He J, Xiong H, Qi M, Yang H, Yang X, Jin Y, et al. Epidemic analysis of human plague caused by Tibetan sheep in Qinghai Province [in Chinese]. Chinese Journal of Epidemiology. 2016;35:354-6 http://www.wanfangdata.com.cn/details/ detail.do?_type=perio\&id=zgdfbxzz201605010

46. Ma Z, Jiang Z. Epidemiological analysis of human plague in Tibet from 1966 to 2012 [in Chinese]. Chinese Journal of Control of Endemic Diseases. 2013;28:119-22 [cited 2021 Aug 11]. http:/ / www.cnki.com.cn/Article/ CJFDTotal-DYBF201302016.htm

47. Bogoch II, Maxim T, Acosta H, Bhatia D, Chen S, Huber C, et al. Potential plague exportation from Madagascar via international air travel. Lancet Infect Dis. 2018;18:247-8. https:// doi.org/10.1016/S1473-3099(18)30077-X

48. Health Commission of Xilinguole League Inner Mongolia. Two plague cases from Xilinguole League have been confirmed 2019 Nov 12 [cited 2021 Aug 11]. http:/ / wjw.xlgl. gov.cn/zwgk_1/dtxx/201911/t20191112_2267734.htm

Address for correspondence: Xin Wang, National Institute for Communicable Disease Control and Prevention, Chinese Center for Disease Control and Prevention, No.155, Changbai Road, Changping, Beijing 102206, China; email: wangxin@icdc.cn 